\title{
Introduction to Fu Sheng Liu Ji, a Chinese Novel and Its English Versions
}

\author{
Qing Zhang \\ Foreign Languages School, Qinghai Normal University, Xining, China \\ Email: 1040198332@qq.com
}

How to cite this paper: Zhang, Q. (2021). Introduction to $\mathrm{Fu}$ Sheng Liu Ji, a Chinese Novel and Its English Versions. Open Journal of Modern Linguistics, 11, 841-848. https://doi.org/10.4236/ojml.2021.116064

Received: November 5, 2021

Accepted: November 21, 2021

Published: November 24, 2021

Copyright (c) 2021 by author(s) and Scientific Research Publishing Inc. This work is licensed under the Creative Commons Attribution International License (CC BY 4.0).

http://creativecommons.org/licenses/by/4.0/

\begin{abstract}
Fu Sheng Liu Ji, a novel written in the Qing Dynasty was a success in literary reform in China. Its unique style attracted many readers as well as researchers. Since it was published, it lacked no translated versions in multiple languages. The thesis will make a general picture of the original work and two of its English versions.
\end{abstract}

\section{Keywords}

Fu Sheng Liu Ji, Shirley M. Black, Lin Yutang

\section{Introduction}

Fu Sheng Liu Ji, a novel written by Shen Fu, a versatile writer in the Qing Dynasty, records his personal life and his travel log. It is a mirror of the scholars' life of that time as well as a vivid picture of people's life in the reign of Qianlong and Jiaqing. It tells us how to appreciate subtle sweetness of ordinary life. It is a completely different style in Chinese literary history. The birth of Fu Sheng Liu $J i$ foretells the beginning of the reform of Chinese literature.

\section{Shen Fu, the Author of Fu Sheng Liu Ji}

Shen Fu's life can be divided into two periods. The first period was from his birth to the eve of the restructuring of his family. In the first period, Shen Fu lived a happy and carefree life, which was dominated by reading, meeting friends, painting and writing poems. In the second period, he was troubled with depression, diseases and poverty. He can be concluded as:

\subsection{A Versatile Scholar}

Shen Fu, was born in Suzhou in 1763. His style name was Sanbai, which means a 
person who leads a simple life and his literary name was Meiyi, which means a person whose sentiments are as advanced as plum blossoms that are symbol of morality in Chinese culture and who pursues nothing mundane. Shen Fu was intelligent and versatile. Besides Fu Sheng Liu Ji, his works also included the painting Garden and the stamp Beautiful Flowers, the Full Moon and Longevity as well as poems such as Sea Watching and A Mountain Trip in Rain, etc. Although he was capable, he still failed to be an official and kept being an ordinary person throughout his life. Even Fu Sheng Liu Ji wasn't paid attention by the literary critics until he passed away.

Besides selling his paintings to make a living, Shen $\mathrm{Fu}$ worked to be an assistant to a ranking official in governments of Anhui, Jiangsu, Yangzhou, Shandong and Hubei; therefore, he was rich in travel experience.

\subsection{A Devoted Husband}

Shen Fu married his cousin named Chen Yun. She was brilliant, good-looking, gentle and refined. She was as brave as her husband when she fought against some feudal customs. Shen and Chen lived happy life with deep love for each other till Chen was dead. Those were old days when women were placed at the bottom of the social ladder. The virtue for them is "Three Obedience" (Rites of Mourning), which means women have to give obeisances and follow spiritual, ethical and moral wisdom of: her father as a maiden daughter; her husband as a chaste wife; her son as a widow in perpetuity dedicated to clan and family and "Four Virtues" ( The Ritual of the Zhou Dynasty), which means women must have morality, proper speech, modest manner, and capability to manage family life. If there were conflicts between parents-in-law and their daughter-in-law, the son had to take side with his parents; otherwise he would be far from being filial. Young couples could not be too intimate after the marriage because their intimacy would allegedly hinder men to succeed in their careers.

Shen Fu and Chen Yun didn't follow the old customs. When they met either in rooms or in gardens they would shake hands and asked "Where are you going?"; they sat on the same bench when they met friends. When Shen Fu learned that Chen Yun did want to go traveling, he told his parents nothing while disguising her as a young man and taking her out. What they did was against the feudal customs as well as Shen Fu's parents' wills; therefore, Chen Yun was disliked by her parents-in-law. They asked Shen Fu to divorce her; otherwise the couple would be chased out of the big family. Facing the choice between "family" and "his wife", Shen Fu chose his wife without a second thought. Although they were troubled with diseases and poverty later, he never ceased to love his wife. Many years after her death, he still loved her as much as ever.

\subsection{A Successful Writer}

In the Qing Dynasty, government officials had too much work so they had to employ some assistants to help them. Shen Fu's father made Shen Fu begin to 
learn how to be an assistant when he was very young, and he officially started the life of an assistant to a ranking official in 1781.

Assistants had no right to make their own decisions on the work, which was against Shen Fu's nature. Furthermore, Shen was romantic, and loved arts and poems more so he was fed up with the life of an assistant. He quit in 1792 and went back home. Since then he opened up his first happy period of life with his beloved wife. Although his parents resented him for his choice, Shen Fu thought that he finally realized his dream.

Shen Fu's father also passed away one year after Chen Yun died. Shen Fu went back home to attend the funeral. After that his younger brother forced him to leave because he was afraid that Shen Fu would share the heritage with him. Shen Fu had neither position in governments nor his own business. He had no choice but to ask one of his friends who was an official in government to help him find a position of an assistant.

In 1808, Qi Kun, the editor of the Imperial Academy made a trip to the Ryukyu State (now Okinawa Prefecture) as an envoy. Many versatile scholars were taken on the trip to complete the task of cultural communication. Shen Fu was one of them. During the trip he and his fellows survived the treacherous sea and he was touched by the idea- "Life is so short" and "our floating life is like a dream". He felt everything was uncertain; therefore, he began to write his memoirs Fu Sheng Liu Ji. At the beginning of the book he wrote "I was born in 1763 under the reign of Ch'ienlung, on the twenty-second day of the eleventh moon. The country was then in the heyday of peace and, moreover, I was born in a scholar's family, living by the side of the Ts'anglag Pavilion in Soochow. So altogether I may say the gods have been unusually kind to me. Su Dongpo once said, 'Life is like a spring dream which vanishes without a trace.' I would be ungrateful to the gods if I did not try to put my life down on record." (Lin Yutang, 1999)

Shen $\mathrm{Fu}$ failed to be an official or a successful businessman, which was unlucky for his family. But it is lucky for Chinese literature because She Fu's personality and life style achieved us a special literature work-Fu Sheng Liu Ji.

\section{On Fu Sheng Liu Ji}

Ancient Chinese literary works can be divided into two types. One was about fantastic and strange stories and only for entertainment. The other type aimed at persuasion and education, in which characters were either evil or perfect. Both of the types touched little on people's real life and inner world.

Fu Sheng Liu Ji took people's real life as the stem so it touches more reality than the other two types.

\subsection{The Layout of Fu Sheng Liu Ji}

Shen Fu composed six chapters in Fu Sheng Liu Ji. They are: chapter one was titled as Wedded Bliss, in which he recorded his happy marriage; chapter two 
was titled as The Little Pleasures of Life, in which he depicted his findings in his life from the period of a young boy to an adult; chapter three was titled as Sorrow, in which his loss of his wife, his father, his son and his wealth was pictured; chapter four was titled as The Joys of Travel, in which was included his travel log; chapter five was titled as Experience, in which he drew conclusions from his life experience and the last chapter was titled as The Way of Life, in which he talked about his opinion on daily life. Unfortunately, the last two chapters are missing.

The title of the book- Fu Sheng Liu Ji, refers to two verses of Li Po's poem, which saysOur floating life is like a dream; how often can one enjoy oneself? (浮 生若梦, 为欢几何? )

$\mathrm{Fu}$ Sheng $\mathrm{Liu} \mathrm{Ji}$ is an autobiographical story mixed with observations and comments on the art of living, the little pleasures of life, and some vivid sketches of scenery, literary and art criticism, all of which makes the work unique in style.

\subsection{The Publication of Fu Sheng Liu Ji}

The extant Chinese version was first published in 1877 by Yang Yichuan, who picked it up from a secondhand bookstore, with the last two chapters missing. According to the author, he was born in 1763 , and the fourth chapter could not have been written before 1808. Wang Tao, a well-known scholar of the time once got a glimpse of the book in his childhood, so it is likely that the book was known in the neighborhood of Suzhou in the second or third decade of the nineteenth century.

\subsection{The Artistic Value of Fu Sheng Liu Ji}

Fu Sheng Liu Ji recorded the life of Chinese scholars of that time. It also mirrored the social situation in the reign of the Emperor Qianlong and Jiaqing. As memoirs, Fu Sheng Liu Ji introduced a new style of literature form that takes scholar's life as a topic. It tells us how to find delicate beauty in ordinary life, how to love life and how to appreciate beautiful things in life. The birth of $F u$ Sheng Liu Ji not only represented progress in Chinese culture but also foretold reform of Chinese literature. Shen $\mathrm{Fu}$, one of the pioneers of the reform of ideology and novels, possesses a significant position in Chinese literary history.

After its publication, Fu Sheng Liu Ji was widely read and was translated into multiple languages, including English, French, Japanese, German and Russian. Lin Yutang not only translated it but also cited it in his book My Country and My People and The Importance of Living.

Although Fu Sheng Liu Ji was special in style and significant in content, literary critics of his time didn't notice it until in 1906 when "novel reform" began. Then it was republished by Yanlaihong Publishing House in Suzhou and became famous in every household.

Fu Sheng Liu Ji has been compared to Hong Lou Meng by Cao Xueqin. Whenever scholars comment on the work they take a graceful and harmonious 
tone and every scholar praises it (Li Fan, 2021). Yu Pingbo, famous Chinese writer and researcher on Hong Lou Meng believed that Shen Fu carefully lived his life and he was touched by his life so much that he pictured what it was in words. Shen $\mathrm{Fu}$ was such an ingenious writer that readers couldn't find any workmanship in his writing. They were just like Shen Fu's neighbour who were witnessing his life (Liu Chang, 2003).

After 1979 scholars began to study Fu Shen Liu Ji from multiple aspects. Some studied its aesthetic value and some studied its style, composition and structure. Now more and more scholars from home and abroad become interested in the study of Fu Sheng Liu Ji.

\section{English Versions of Fu Sheng Liu Ji}

There are four English versions of Fu Sheng Liu Ji. The author will focus on the one translated by Shirley M. Black, a British expert in Chinese and the one translated by Lin Yutang, a famous Chinese scholar and translator as the two versions are different in many ways.

\subsection{Shirley M. Black's Version of Fu Sheng Liu Ji}

Shirley M. Black, an expert in Chinese, translated Fu Sheng Liu Ji in 1959 and her version was published by Oxford University Press in 1960.

Shirley chose the book because she appreciated the life and culture depicted in it. She introduced it as a literary masterpiece that was poetic, romantic, nostalgic, and sentimental. In her translation, she tried to reproduce the subtle emotional atmosphere created by Shen Fu in Fu Sheng Liu Ji. Besides, she made efforts to express every word in the original work exactly while keeping transferring the feelings of Shen Fu to her readers in mind.

She titled the version Chapters from a Floating Life-The Autobiography of a Chinese Artist. The original six chapters are divided into three parts in Shirley's translated version. There are 7 chapters in part one, one chapter in part two and four chapters in part three. Furthermore, she omitted many episodes from the fourth part, originally named as The Joys of Travel, which was about the visits to temples and scenic places because she thought they were rather alike and would not mean much to the readers unacquainted with the actual places described in the original work. She also left out some sections of literary criticism, gardening and botany because she felt they were too specialized to be understood by readers. Then she rearranged the rest episodes into a chronological order which she thought that would be less confusing.

As for translation strategies, Shirley M. Black mainly adopted domestication. Domestication cleans out reading hurdles for target readers while it also blocks their knowledge of culture in other countries. Besides the neat six-chapter structure of the original work was changed into 12 chapters, which changed the unique literary style the original work enjoys. Shirley also adjusted the sequence of the book. For example, she put the content of the original Chapter two (The Little 
Pleasure of Life) in her first chapter as she thought it reasonable for readers to know what kind of person the author was before they know other things.

Although Shirley knew Chinese well, she still misunderstood some idioms. For example, she mistranslated “衣冠之家” into “a full-dress family” instead of its real meaning “a scholar's family”, “花烛之夕” into “our wedding candles burned, at dusk" instead of its original meaning "our wedding took place" and “明察秋毫” into “see very clearly such minute autumn hairs". These mistakes will make readers confused and even led misunderstanding of the Chinese culture (Shirley M. Black, 1960).

\subsection{Lin Yutang's Version of Fu Sheng Liu Ji}

"Standing in the eastern and western cultures are my feet, criticizing the articles in the Cosmos is my whole heart" and "Articles can be humorous, work must be conscientious" were two aphorisms that encouraged Lin Yutang to be himself throughout his life. He advocated the literary style of Hsingling (性灵), which means that literary works must reveal the author's personal nature, and Hjinqing (近情), which means to be humane and humor. He advocated the sense of humor. It was Lin Yutang who rendered "humor" for the first time into “幽默” in Chinese, and coined a new Chinese phrase and consequently won the accolade of "Master of Humor" (Wang Zhaosheng, 2006).

As a translator, Lin Yutang had his own thoughts on translation, which can be concluded as "faithfulness, expressiveness and aesthetics.

Lin Yutang's English version of Fu Sheng Liu Ji, titled as Six Chapters of a Floating Life was first published in 1939 and republished in 1942. The author will focus on the version published in 1939.

The layout of this version is the same as the original works because he wanted the target readers to learn Chinese culture by reading the novel.

There were several reasons for Lin Yutang to translate Fu Sheng Liu Ji. The first reason is that some of his emotion to the life coincides with the tragic tone of the novel. Lin Yutang loved everything alive but he knew those wouldn't last forever; therefore, he felt sad while he enjoyed the living world (Wang Zhaosheng, 2006). He said in the preface "The reference is to two verses in Li Po's poem, 'Our floating life is like a dream; how often can one enjoy oneself?'” (Lin Yutang, 1999) Obviously, Shen Fu had set a sad tone for his novel when he took "a floating life" as key words and Lin Yutang fully understood what Shen Fu meant.

The second reason is that the character "Chen Yun" influenced Lin Yutang very much. Lin admired her. He once praised "Yun" as one of the loveliest women in Chinese literature. He didn't think she was the most beautiful as the author, her husband, did not make the claim. In Lin Yutang's opinion, she was brave because she could tell her husband that she wanted to travel outside the house and she agreed with her husband's idea to disguise her as a young man in order to avoid her in-laws' prevention. Her bravery made the scene of the vast 
Taihu Lake and the full moon over the water very distinctive (Lin Yutang, 1999).

The third reason is that Lin Yutang was haunted by the question of what happiness was while reading and rereading Fu Sheng Liu Ji. He said "For those who do not know it, happiness is a problem; and for those who do know it, happiness is a mystery." (Lin Yutang, 1999) When he read Fu Sheng Liu Ji, he had the sense of mystical happiness, which transcends all bodily sorrow or actual hardship.

As for translation strategies, Lin Yutang adopted foreignization as he wanted his readers to know more about the society and culture depicted in Shen Fu's work. Lin Yutang defined "faithfulness" in translation in three aspects which were furthered divided into four implications; that is, 1) Faithfulness does not mean word for word translation. 2) Faithfulness means to be expressive with the meaning and "conveying the feeling-tone". 3) The standard of faithfulness means the impossibility of absolute faithfulness. 4) The standard of faithfulness means expressiveness (Dong Hui, 2002). In accordance with his own reflections on translation, Lin Yutang transmitted the leisure, beauty and sentiment embedded in Shen Fu's work to his readers. For example, in Lin's translation “花烛之夕” was translated into “Our wedding took place”, “衣冠之家” into “a scholar’s family” and “明察秋毫” into “see the tiniest objects” (Lin Yutang, 1999). Lin Yutang was good at both Chinese and English; which enabled his version of $\mathrm{Fu}$ Sheng Liu Ji more faithful (Dong Hui, 2002).

\section{Conclusion}

Although Shen Fu failed to be an official and made his parents disappointed, he succeeded in creating a new style of literary work in China, which started to pay attention to real life of ordinary people.

Both Lin Yutang and Shirley M. Black contributed to the spread of Chinese literary work to the world and let readers from English world have a chance to glimpse at Chinese scholars' life in the Qing Dynasty. Although there are small problems in Shirley's translation, these were dwarfed by her contribution as she led her readers to know Chinese culture in a different aspect. Although Lin Yutang's translation is more faithful to the original work, there is still room to improve in modern time.

Besides the textual study on the two versions, there are other fields for researchers to probe, including comparison of the acceptance of the two versions in English world, study on the other English versions of Fu Sheng Liu Ji and analysis of the subjectivity of different translators to make researches on Fu Sheng Liu Ji more completed.

\section{Conflicts of Interest}

The author declares no conflicts of interest regarding the publication of this paper.

\section{References}

Black, S. M. (1960). Chapters from a Floating Life-The Autobiography of a Chinese Art- 
ist. Oxford University Press.

Dong, H. (2002). Skillfull and Miraculous Translation-Appreciation and Analysis of the English Version of Fu Sheng Liu Ji Translated by Lin Yutang. The Academic Journal of Xi'an International Studies University, 3, 11-15.

Li, F. (2021). Study on the Poetic and Tenderness Revealed by the Novel Fu Sheng Liu Ji. Qiqihar: Youth Literator, 11, 82-83.

Lin, Y. T. (1999). Six Chapters of a Floating Life. FLTRP.

Liu, C. (2003). Study on Domestication and Foreignization Applied in Two English Versions of Fu Sheng Liu Ji. The Academic Journal of UESTC (Social Science Edition), 4, 77-80.

Wang, Z. S. (2006). Lin Yutang's Biography. The Writer's Publish House Co. Ltd. 